\title{
Article
}

\section{Kaempferol Inhibits Zearalenone-Induced Oxidative Stress and Apoptosis via the PI3K/Akt-Mediated Nrf2 Signaling Pathway: In Vitro and In Vivo Studies}

\author{
Peramaiyan Rajendran ${ }^{1, *},+\left(\mathbb{D}\right.$, Rebai Ben Ammar ${ }^{1,2} \mathbb{C}^{-}$, Fatma J. Al-Saeedi ${ }^{3,+}{ }^{+}$, Maged E. Mohamed ${ }^{4,5}$, \\ Medhat A. ElNaggar ${ }^{6,7}$ (), Saeed Y. Al-Ramadan ${ }^{8}$, Gamal M. Bekhet ${ }^{1,9}$ and Ahmed M. Soliman ${ }^{10,11(\mathbb{D})}$
}

check for

updates

Citation: Rajendran, P.; Ammar, R.B.; Al-Saeedi, F.J.; Mohamed, M.E.; ElNaggar, M.A.; Al-Ramadan, S.Y.; Bekhet, G.M.; Soliman, A.M. Kaempferol Inhibits Zearalenone-Induced Oxidative Stress and Apoptosis via the PI3K/Akt-Mediated Nrf2 Signaling Pathway: In Vitro and In Vivo Studies. Int. J. Mol. Sci. 2021, 22, 217. https://dx.doi.org/10.3390/ ijms22010217

Received: 8 November 2020 Accepted: 9 December 2020 Published: 28 December 2020

Publisher's Note: MDPI stays neutral with regard to jurisdictional claims in published maps and institutional affiliations.

Copyright: () 2020 by the authors. Licensee MDPI, Basel, Switzerland. This article is an open access article distributed under the terms and conditions of the Creative Commons Attribution (CC BY) license (https: / / creativecommons.org/ licenses/by/4.0/).
1 Department of Biological Sciences, College of Science, King Faisal University, Al-Ahsa 31982, Saudi Arabia; rbenammar@kfu.edu.sa (R.B.A.); gbekhet@kfu.edu.sa (G.M.B.)

2 Laboratory of Aromatic and Medicinal Plants, Center of Biotechnology, Technopole of Borj-Cedria, Hammam-Lif 901 2050, Tunisia

3 Department of Nuclear Medicine, Faculty of Medicine, Kuwait University, Safat 13110, Kuwait; fatma.alsaeedi@ku.edu.kw

4 Pharmaceutical Sciences Department, College of Clinical Pharmacy, King Faisal University, Al-Ahsa 31982, Saudi Arabia; memohamed@kfu.edu.sa

5 Pharmacognosy Department, College of Pharmacy, Zagazig University, Zagazig 44519, Egypt

6 Plant Pathology Research Institute, Agricultural Research Center, Giza Governorate 12619, Egypt; drnaggar@sago.gov.sa

7 Research Central Laboratory, Saudi Grains Organization, Riyadh 11471, Saudi Arabia

8 Department of Anatomy, College of Veterinary Medicine, King Faisal University, Al-Ahsa 31982, Saudi Arabia; salramadan@kfu.edu.sa

9 Department of Zoology, Faculty of Science, Alexandria University Egypt, Alexandria 21544, Egypt

10 Department of Arid Land Agriculture, College of Agricultural \& Food Sciences, King Faisal University, Al Ahsa 31982, Saudi Arabia; amohamed@kfu.edu.sa

11 Virus \& Phytoplasma Research Department, Plant Pathology Research Institute, Agricultural Research Center, Giza Governorate 1266, Egypt

* Correspondence: prajendran@kfu.edu.sa; Tel.: +966-5899543; Fax: +966-013-5899556

+ These authors contributed equally to this work.

Abstract: In this study, kaempferol (KFL) shows hepatoprotective activity against zearalenone (ZEA)-induced oxidative stress and its underlying mechanisms in in vitro and in vivo models were investigated. Oxidative stress plays a critical role in the pathophysiology of various hepatic ailments and is normally regulated by reactive oxygen species (ROS). ZEA is a mycotoxin known to exert toxicity via inflammation and ROS accumulation. This study aims to explore the protective role of KFL against ZEA-triggered hepatic injury via the PI3K/Akt-regulated Nrf2 pathway. KFL augmented the phosphorylation of PI3K and Akt, which may stimulate antioxidative and antiapoptotic signaling in hepatic cells. KFL upregulated Nrf2 phosphorylation and the expression of antioxidant genes HO-1 and NQO-1 in a dose-dependent manner under ZEA-induced oxidative stress. Nrf2 knockdown via small-interfering RNA (siRNA) inhibited the KFL-mediated defence against ZEA-induced hepatotoxicity. In vivo studies showed that KFL decreased inflammation and lipid peroxidation and increased $\mathrm{H}_{2} \mathrm{O}_{2}$ scavenging and biochemical marker enzyme expression. KFL was able to normalize the expression of liver antioxidant enzymes SOD, CAT and GSH and showed a protective effect against ZEA-induced pathophysiology in the livers of mice. These outcomes demonstrate that KFL possesses notable hepatoprotective roles against ZEA-induced damage in vivo and in vitro. These protective properties of KFL may occur through the stimulation of Nrf2/HO-1 cascades and PI3K/Akt signaling.

Keywords: zearalenone; kaempferol; PI3K/Akt; hepatotoxicity; Nrf2; apoptosis 


\section{Introduction}

Fungal mycotoxins are produced naturally and infect a wide range of farm produce. Since they are specific to food products and are highly likely to impact human health and livestock and poultry production, mycotoxins are harmful to animals and humans worldwide [1,2]. Zearalenone (ZEA) is an oestrogenic mycotoxin responsible for polluting cereal grains, for instance oats, barley or sorghum across the globe. Many studies have shown that ZEA and its metabolites may be ingested and lead to various harmful effects on reproductive system, hepatocytes and kidney cells [3-5]. When ZEA enters the body of either animals or human beings, it passes through the hepatic and systemic vessels before reaching another target organ [3]. The liver has a significant role in carrying out detoxification of foreign substances along with elimination of metabolites. Reactive metabolites produce ROS during the biotransformation of foreign substances. Numerous chronic diseases are associated with ROS. Liver cirrhosis represents a condition in which oxidation and oxidation resistance are clearly imbalanced [6,7]. ROS are induced through the phosphoinositide 3-kinase (PI3K)/Akt pathway, which triggers various intracellular responses [8-10]. Hence, PI3K/Akt pathway significantly helps in providing cellular defense against inflammatory stimuli. Numerous studies have shown that multiple signal transduction mechanisms, such as PI3K/Akt, make Nrf2 dissociate from Keap1 and facilitate subsequent signal transduction to induce the activation of antioxidant enzymes [11-13], and also have demonstrated that continuous oxidative stress leads to the downregulation of cell survival PI3K/Akt signaling [14-16]. The regulation of PI3K/Akt signaling routes may therefore be a promising strategy for preventing ROS-induced hepatic apoptosis.

On other hand, numerous previous reports have demonstrated that natural compounds have several properties in inhibiting hepatic apoptosis. Flavonoids are antioxidants that are present in a wide range of plants and are abundant in nature. Kaempferol (3,5,7-trihydroxy-2-(4-hydroxyphenyl)-4H-1-benzopyran-4-one) represents the maximum encountered aglycone flavonoids. Its antioxidant and anti-inflammatory properties have been illustrated in numerous ailments such as diabetes, encephalomyelitis, carcinogenesis and asthma. Furthermore, KFL can effectively scavenge free radicals and preserve the functions of antioxidants $[17,18]$. This research aims to investigate the impact of KFL on ZEA-induced oxidative stress and apoptosis via PI3K/Akt pathway both in vitro and in vivo to elucidate the fundamental molecular mechanisms.

\section{Results}

\subsection{KFL Inhibits Hepatotoxicity Induced by ZEA in HepG2 Cells}

HepG2 cells were added to recommended amounts of ZEA for 24 and $48 \mathrm{~h}$, as depicted in Figure 1B. ZEA reduced the viability of the cell in a dose-dependent and time-dependent manner. However, the cells treated with only with KFL alone did not differ in terms of viability from the control cells (Figure 1C), and in cells with KFL and ZEA, KFL protected cells from ZEA-induced cell death in a dose-dependent manner (Figure 1D). Overall, the above data showed that KFL potentially inhibits ZEA-induced hepatotoxicity.

\subsection{ZEA Inhibits the Expression of Nrf2, HO-1 and NQO1 in HepG2 Cells}

Nrf2 is an essential component in cells that is implicated in oxidative stress. During oxidative stress, Nrf2 can induce the expression of a variety of protective proteins (HO-1 and NQO1) to regulate oxidative stress [19]. We further assessed if ZEA would have an inhibitory role in Nrf2, HO-1 and NQO1 expression on the basis of Western blotting data, and the outcomes showed that ZEA significantly downregulated the expression of Nrf2, HO-1 and NQO1 in a dose-dependent manner, as demonstrated in Figure 2A. 
<smiles>O=c1c(O)c(-c2ccc(O)cc2)oc2cc(O)cc(O)c12</smiles>

Kaempferol (3,4',5,7-tetrahydroxyflavone)

B

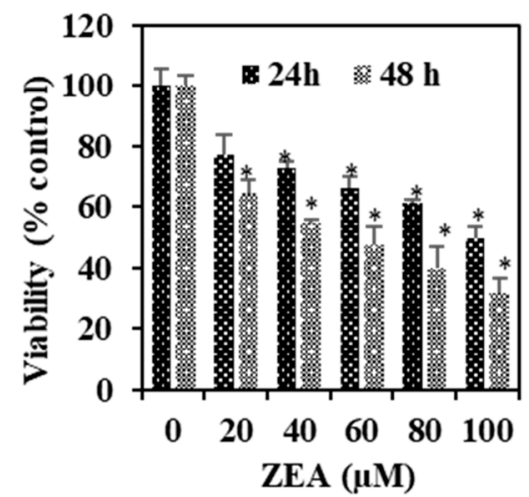

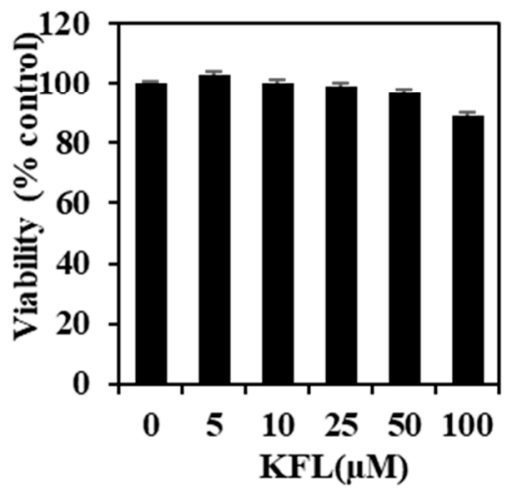

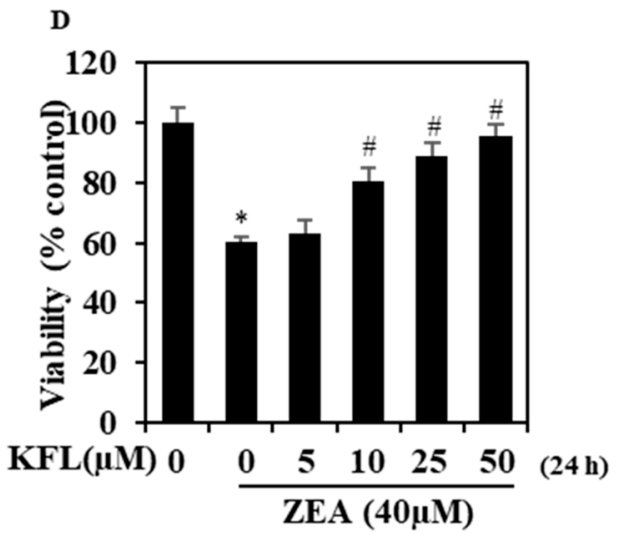

Figure 1. Impact of zearalenone (ZEA) and kaempferol (KFL) on viability. (A) Chemical structure of kaempferol. (B) HepG2 cells were added with the indicated dosages of ZEA for $24 \mathrm{~h}$ and $48 \mathrm{~h}$, and then viability was determined through MTT assay. (C) Cytotoxic effect of KFL on HepG2 cells. Cells were exposed to different concentrations of KFL for $24 \mathrm{~h}$. (D) KFL protects the cytotoxic effect of ZEA $(24 \mathrm{~h})$ as analyzed by MTT assay. Data are represented as the mean $\pm \mathrm{SD}$ of triplicate values $(n=3)$, and $* p<0.05$ represents significant difference in comparison to the control group. \# $p<0.05$ represents significant variations compared the ZEA alone and KFL with ZEA treatment groups. 
A
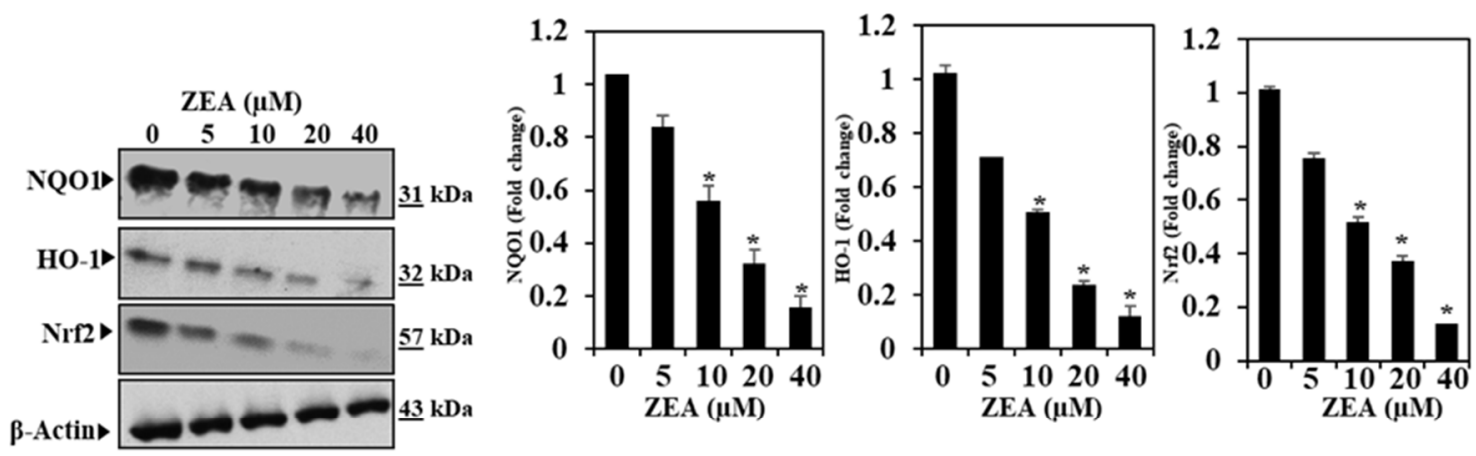

B

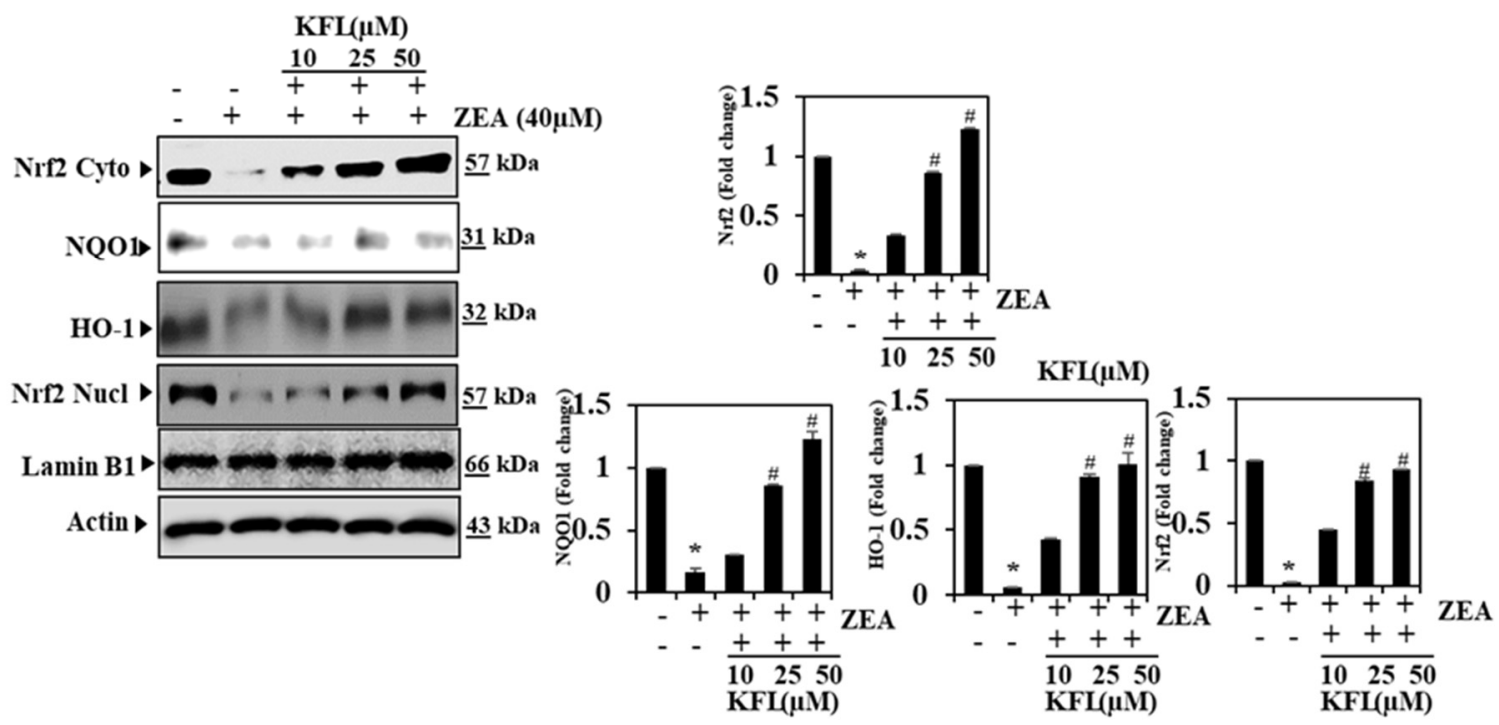

Figure 2. KFL induces nuclear factor-erythroid 2-related factor 2-dependent haem oxygenase-1 (HO-1) expression in ZEA-treated HepG2 cells. (A) Cells were incubated with various concentrations of ZEA for $24 \mathrm{~h}$, and equal amounts of whole-cell lysate were exposed to SDS-PAGE. Membranes probed with anti-NQO1, anti-HO-1 and anti-Nrf2 antibodies. (B) Cells were treated with KFL $(50 \mu \mathrm{M})$ and/or ZEA $(40 \mu \mathrm{M})$ for $24 \mathrm{~h}$, and the Western blotting results show the effects of KFL on the protein levels of HO-1, NQO-1, and Nrf2 in the cytosolic and nuclear fractions. The relative ratios of expression in the Western blotting results are demonstrated below each of the results as values relative to actin expression. Data are represented as the mean $\pm \mathrm{SD}$ of triplicate values $(n=3)$, and ${ }^{*} p<0.05$ represents significant variations compared with the control. \# $p<0.05$ represents remarkable variations compared the ZEA alone and KFL with ZEA treatment groups.

\subsection{Effects of KFL on Nrf2-Related Protein Expression in ZEA-Induced Hepatic Cells}

Since KFL stimulates the Nrf2/HO-1/NQO1 pathway [20] (Figure S1), we assessed whether KFL activates the Nrf2/HO-1/NQO1 pathway in ZEA-supplemented cells. Based on Western blotting and qRT-PCR, it was found that the proteins were significantly $(p<0.05)$ upregulated in cells pre-treated with KFL, compared to cells treated with ZEA alone (Figures 2B and 3A). These data suggest that KFL ameliorates ZEA-induced oxidative stress by upregulating Nrf2. 
$\mathbf{A}$
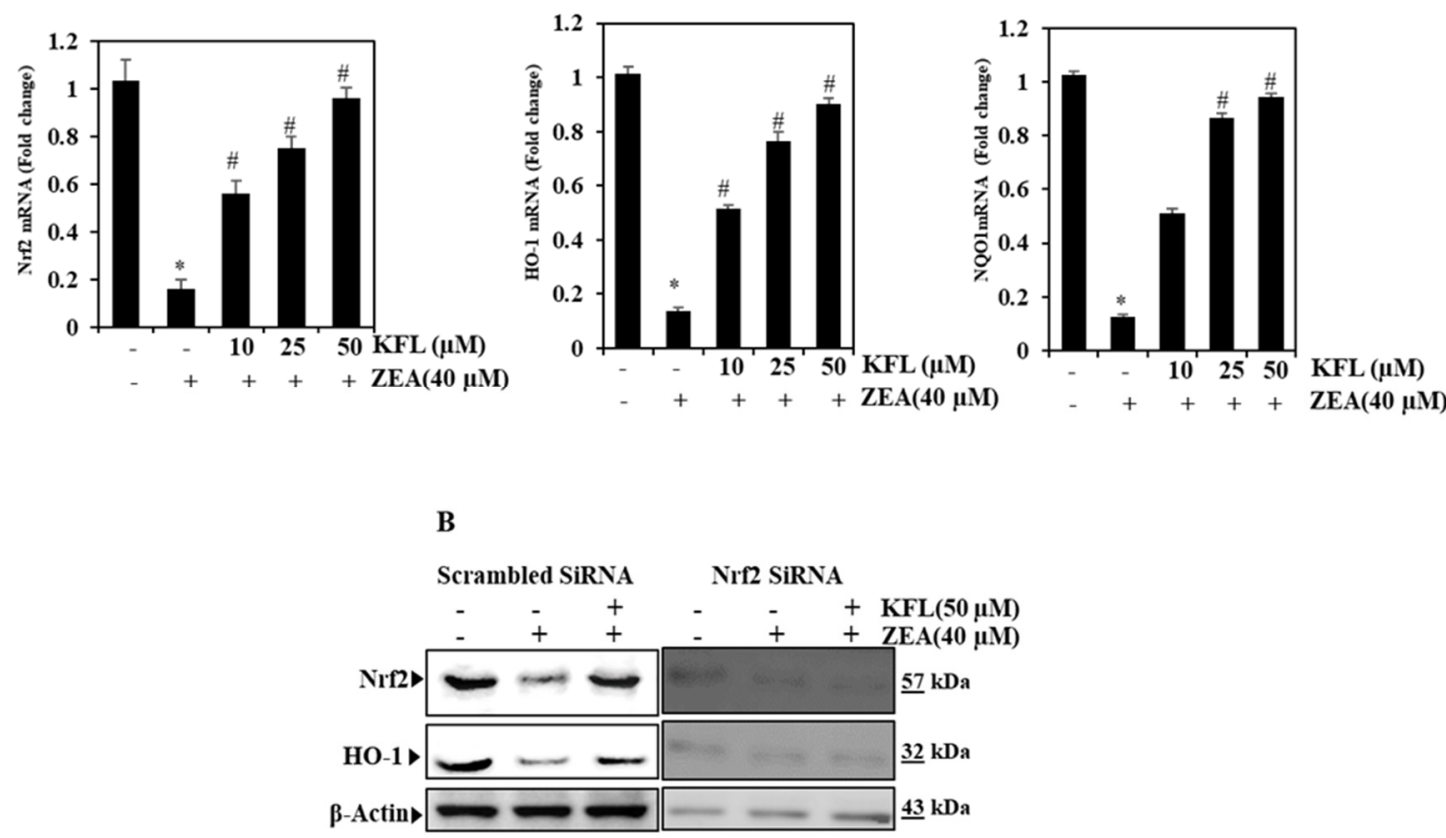

Figure 3. KFL up-regulates the antioxidant markers Nrf2, NQO-1 and HO-1 in HepG2 cells. (A) Nrf2, NQO-1 and HO-1 expression analyzed by RT-PCR. (B) The effects of inhibiting Nrf2 by siRNA transfection were studied by protein analysis. Cells were transiently transfected with Nrf2 siRNA at 100 pM per well in 6-well plates for $24 \mathrm{~h}$, followed by treatment with ZEA and/or KFL for $24 \mathrm{~h}$. SDS-PAGE was used to detect the expression of Nrf2 and HO-1 proteins. Data are represented as the mean \pm SD of triplicate values $(n=3)$, and ${ }^{*} p<0.05$ denotes remarkable variations as compared to the control. \# $p<0.05$ denotes remarkable variations compared the ZEA alone and KFL with ZEA treatment groups.

\subsection{The Oxidative Stress Effect of KFL Is Attenuated by Nrf2 Knockdown}

The signaling of Nrf2, which is crucially implicated in ROS-mediated hepatic fibrosis, intensifies oxidative stress and aggravates fibrotic pathology through downregulating Nrf2 expression [21]. To further confirm that KFL activates Nrf2 in ZEA-treated HepG2 cells, we performed knockdown studies and analysis Nrf2 and HO-1 expression by Western blotting. As Figure 3B demonstrates, Nrf2 expression was abolished in siRNA-transfected cells, even in cells pre-treated with KFL and ZEA. Based on this result, KFL may activate antioxidant systems via Nrf2 signaling.

\subsection{KFL Could Potentially Up-Regulate Phospohrylation of PI3K/Akt Expression}

Some of the key concerns are that inhibitors of pPI3K/pAkt increase liver and inflammation as well as the risk of hepatic cancer because hepatic elimination from Akt contributes to chronic liver damage, inflammation and hepatocellular carcinoma (HCC) [22]. Consequently, we further verified the influence of KFL in inhibiting ZEA-induced oxidative stress by PI3K/Akt signaling pathway through Western blotting. In the present study, we found that ZEA alone $(40 \mu \mathrm{M})$ could downregulate $\mathrm{pPI} 3 \mathrm{~K} / \mathrm{pAkt}$ activation, as shown in Figure $4 \mathrm{~A}$; however, after treatment with KFL and ZEA, the activation of the pPI3K/pAkt was significantly $(p<0.05)$ upregulated in a dose-dependent manner. Therefore, KFL could protect against ZEA-induced oxidative stress via the PI3K/Akt pathway. 
$\mathbf{A}$

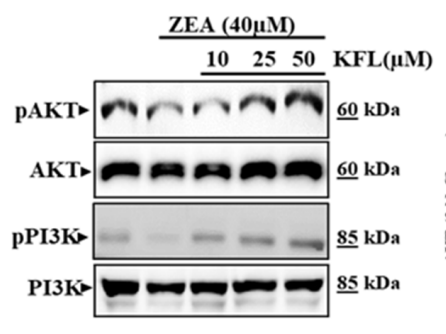

B
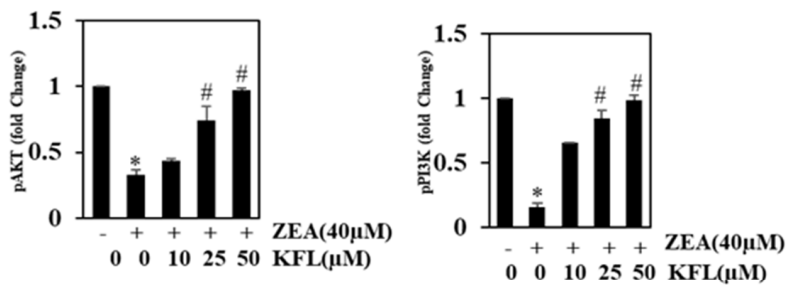
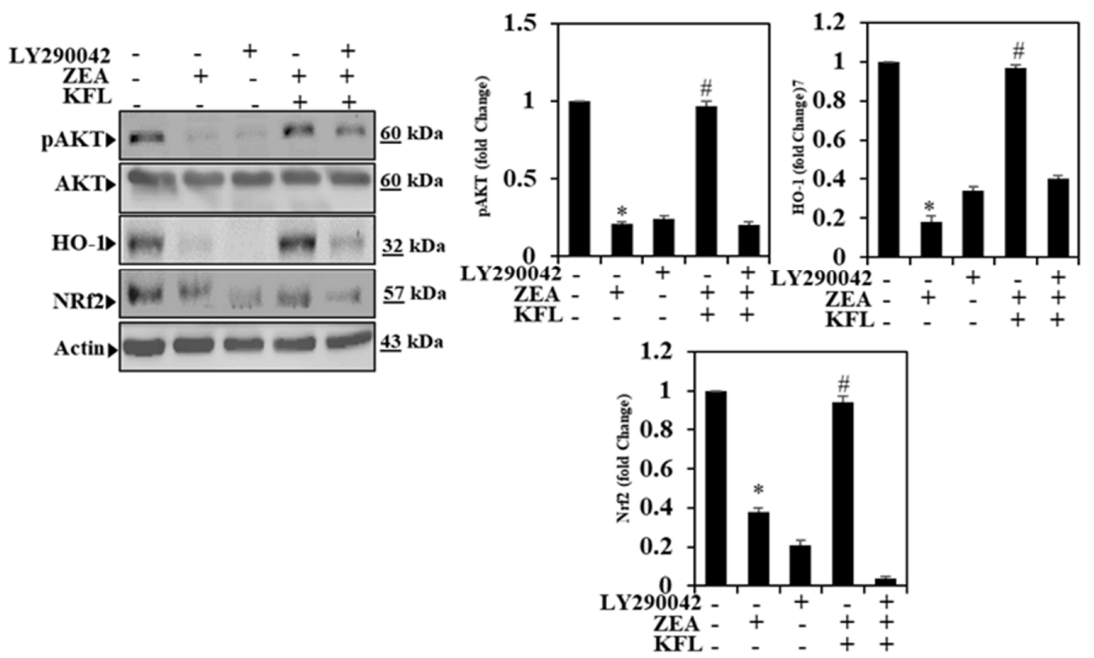

Figure 4. KFL triggers the PI3K/Akt pathway in ZEA-induced HepG2 cells. (A) Cells were treated with KFL (10, 25 and $50 \mu \mathrm{M})$ followed by ZEA $(40 \mu \mathrm{M})$ for $24 \mathrm{~h}$. After the treatment, whole-cell lysates were exposed to Western blotting with anti-pPI3K and anti-pAkt antibodies. Total PI3K and Akt levels were measured as loading controls. (B) Cells were pre-treated with a PI3K/Akt inhibitor (LY294002, $30 \mu \mathrm{M})$ for $2 \mathrm{~h}$, followed by KFL (50 $\mu \mathrm{M})$ and/or ZEA (40 $\mu \mathrm{M})$ for $24 \mathrm{~h}$. Western blot was performed to detect the pAkt, HO-1 and Nrf2 levels by anti-pAkt, anti-HO-1 and anti-Nrf2 abs. Data are represented as the mean $\pm \mathrm{SD}$ of triplicate values $(n=3)$, and ${ }^{*} p<0.05$ represents noteworthy discrepancies compared with the control. \# $p<0.05$ represents significant variations compared with the ZEA alone and KFL with ZEA treatment groups.

\subsection{KFL Activates PI3K/Akt Signalling to Regulate Nrf2 in ZEA-Induced Hepatic Cells}

To testify if the up-regulation of pAkt is linked to with Nrf2 signals, stimulation of Akt protein was examined using Western blotting. Here, the selective inhibitor LY294002 was used to determine the crucial role of PI3K/Akt in the activation of Nrf2 signaling in KFL pre-treated cells with ZEA. As shown in Figure 4B, ZEA with KFL-treated cells has upregulated pAkt, Nrf2 and HO-1 compared to control cells; however, cells treated with LY294002, KFL and ZEA combined, had significantly downregulated levels of these proteins. Therefore, KFL may rely on the regulation of PI3K/Akt-Nrf2 signaling in HepG2 cells.

\subsection{KFL Suppressed ZEA-Induced DNA Damage}

Many studies have established that ZEA induces DNA damage and leads to apoptosis [23-25]. We examined if KFL is responsible for causing DNA damage induced by ZEA by Western blotting. We found that the expression of the DNA damage marker protein $\gamma-\mathrm{H} 2 \mathrm{~A}$ in ZEA-treated cells was significantly elevated $(p<0.05)$, while in KFL pre-treated cells also treated with ZEA, we found that $\gamma$-H2A protein expression is inhibited in a dose-dependent manner by KFL. These results indicate that KFL may inhibit DNA damage induced by ZEA in hepatic cells (Figure 5A). Additionally, augmented DNA fragmentation 
was noticed in KFL (50 $\mu \mathrm{M})$ and/or ZEA-treated HepG2 cells (Figure 5B). ZEA-treated cells showed significantly elevated DNA fragmentation, on the other hand, in cells pre-treated with KFL, this effect was reversed to normal. These outcomes reveal that KFL can inhibit ZEA-induced DNA fragmentation in HepG2 cells.

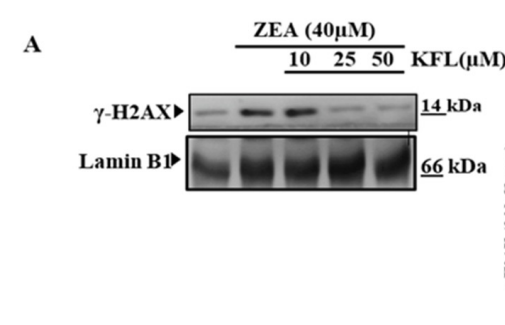

C

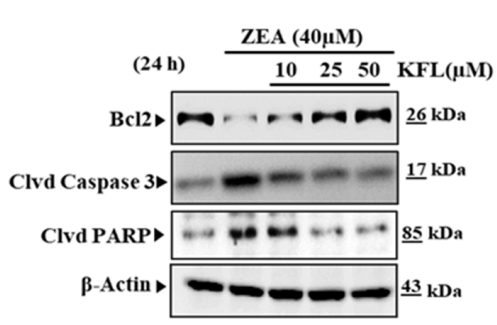

D

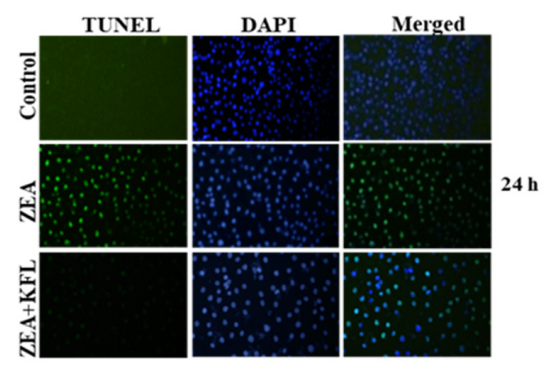

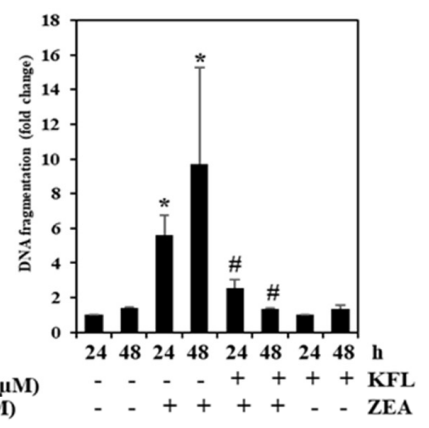
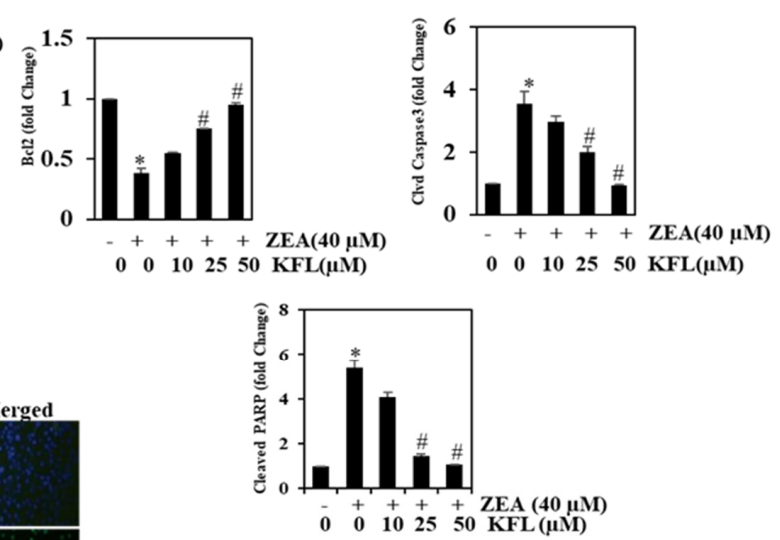

Figure 5. KFL repressed DNA damage and apoptosis induced by ZEA in HepG2 cells (A) $\gamma$-H2AX nuclear protein expression analyzed and $\gamma-\mathrm{H} 2 \mathrm{AX}$ normalized to Lamin B1. (B) DNA fragmentation (C) HepG2 cells were treated with the KFL and/or ZEA for $24 \mathrm{~h}$. Expression of BCL2, cleaved caspase-3 (clvd Caspase3) and cleaved PARP (clvd PARP) protein was assessed by Western blotting. (D) KFL protected against ZEA-induced apoptosis ( $24 \mathrm{~h}$ ), as indicated by TUNEL assay. Data are represented as the mean \pm SD of triplicate values $(n=3)$, and $* p<0.05$ represents significant variations compared with the control. \# $p<0.05$ represents significant variations as compared to ZEA alone and KFL with ZEA treatment groups.

\subsection{KFL Inhibits Apoptosis in ZEA-Induced Hepatic Cells}

Hepatic necrosis is a major indication of underlying liver failure. ZEA causes apparent apoptosis and necrosis at higher concentrations [26]. In the end, we also analyzed whether KFL could inhibit ZEA-induced apoptosis in hepatic cells. The results from Figure 5C show that ZEA markedly inhibited $\mathrm{Bcl} 2$ expression and subsequently elevated the levels of apoptosis marker proteins cleaved caspase- 3 and cleaved PARP. The down-regulation of $\mathrm{Bcl} 2$ and up-regulation of cleaved protein levels were markedly reversed when cells were treated with KFL. These data suggested that KFL suppressed ZEA-induced apoptosis in HepG2 cells. The data from the TUNEL assay (Figure 5D) clearly show that KFL treatment can inhibit HepG2 cell apoptosis. Overall, the above-mentioned data demonstrate that KFL potentially inhibits ZEA-induced hepatotoxicity. 


\subsection{KFL Potentially Inhibits ZEA Induced Toxic Effects}

When body weight and liver morphology there no statistically marked difference between the control and experimental groups (Supplementary Table S1 and Figure S2). Supplementary video file showed animal behavioural studies, control animals have shown normal behaviour (Video S1), ZEA alone treated animal has shown abnormal behaviour, agitated and fight with others (Videos S2 and S3), KFL with ZEA treated and KFL alone treated animals have shown normal behaviour and activity (Videos S4 and S5).

\subsection{KFL Potentially Inhibits Pro-Inflammatory Cytokines}

Comprehensive studies have shown that key genes mediate hepatic damage. Hepatocellular necrosis controlling genes and inflammation influence the degree of liver damage $[27,28]$. We also examined the anti-inflammatory influence of KFL on mice injected with ZEA using ELISA. The serum levels of IL-6, TNF- $\alpha$ and IL- $\beta 1$ were noted to be significantly higher $(p<0.05)$ in mice treated only with ZEA, whereas IL-6, TNF- $\alpha$ and IL-1 $\beta$ were inhibited by KFL. The levels of IL-6, TNF- $\alpha$ and IL-1 $\beta$ in KFL with ZEA-treated mice nearly reached the control levels (Figure 6B-D). KFL-treated mice showed no differences in comparison to the control mice. The obtained outcomes revealed that KFL has a potent cytoprotective effect against ZEA-induced toxicity.
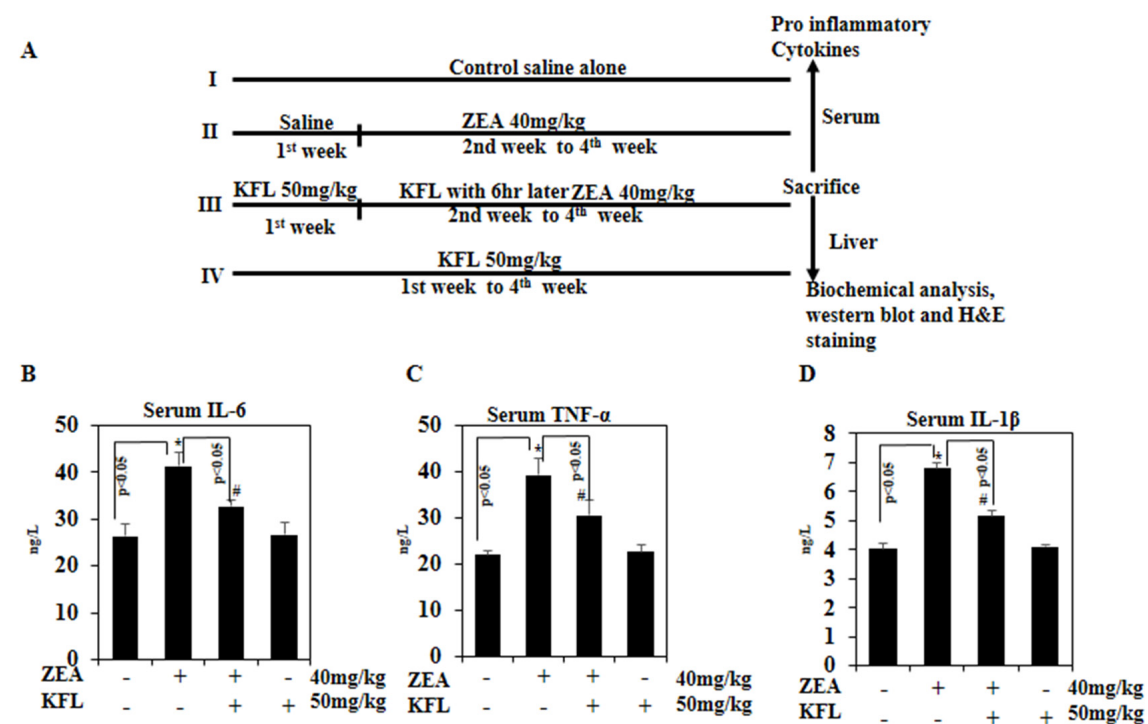

E

$\mathbf{F}$

G
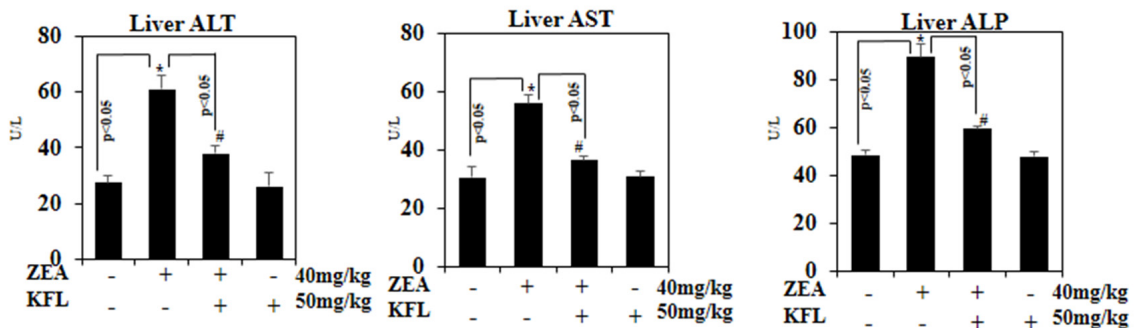

Figure 6. Effect of KFL on pro-inflammatory cytokines in ZEA-treated mice. (A) Schematic of the animal experimental method. (B-D) ELISA was used to quantity the levels of the pro-inflammatory cytokines (B) IL-6, (C) TNF- $\alpha$ and (D) IL-1 $\beta$ in mouse serum. (E-G) The level of liver markers was analyzed by ELISA: (E) ALT, (F) AST and (G) ALP. Data are expressed as the mean values $\pm S D$ of independent experiments $(n=6) ;{ }^{*} p<0.05$ represents significant variations in the ZEA alone group compared with the control group. \# $p<0.05$ represents significant variations compared the ZEA alone and KFL with ZEA treatment groups. 


\subsection{KFL Inhibits Hepatic Marker Enzyme Activity}

Aminotransferases (ALT and AST) are hepatocellular damage markers. As shown in Figure $6 \mathrm{E}-\mathrm{G}$, the ZEA-treated mice exhibited increased activities of AST, ALT and ALP compared to those of the control animals. However, ZEA with KFL-treated mice had markedly $(p<0.05)$ decreased activation of the above enzymes. Moreover, mice treated with KFL alone did not show any significant differences from control animals. This study demonstrated that KFL could mitigate ZEA-induced liver toxicity.

\subsection{Effect of KFL on ROS Production}

In various types of liver diseases, there is a marked involved of ROS-mediated oxidative stress. The endogenous antioxidants that subsequently fail to counteract all the ROS leading to cellular injury are excessively ROS-produced [29]. Hence, we have determined $\mathrm{H}_{2} \mathrm{O}_{2}$ production in liver control and experimental animals. The production of $\mathrm{H}_{2} \mathrm{O}_{2}$ was markedly $(p<0.05)$ augmented in ZEA-treated mice compared to control mice. In contrast, KFL with ZEA-treated mice showed downregulation of $\mathrm{H}_{2} \mathrm{O}_{2}$ production when compared to ZEA-treated mice (Figure 7A).

A

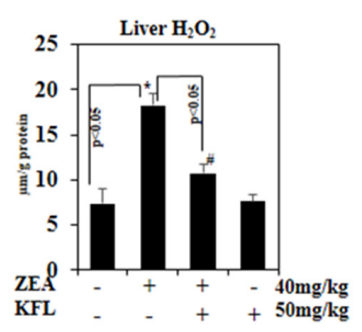

D

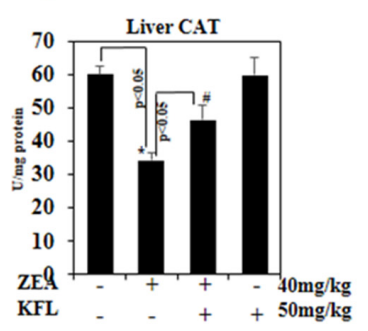

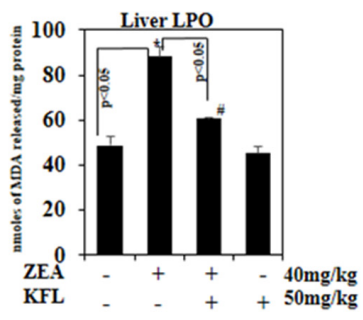

E

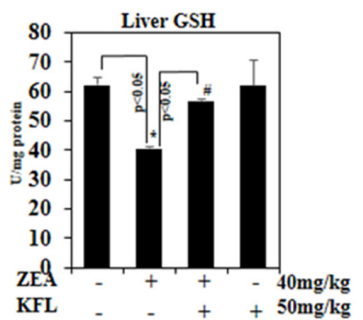

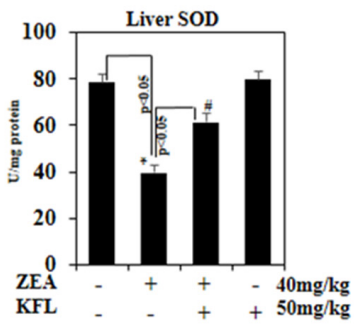

Figure 7. Effect of KFL on ZEA-induced ROS accumulation and antioxidant systems in mouse livers. (A) $\mathrm{H}_{2} \mathrm{O}_{2}$, (B) LPO, (C) SOD, (D) CAT and (E) GSH. ELISA kits were used based on the manufacturer's directions (units: $\mathrm{H}_{2} \mathrm{O}_{2}, \mu \mathrm{m} / \mathrm{g}$ protein; $\mathrm{LPO}, \mathrm{nM}$ of MDA released/mg protein; SOD, CAT and GSH, U/mg protein). Data are expressed as the mean values \pm SD of independent experiments $(n=6)$. ${ }^{*}$ Significant in the ZEA alone group compared with the control group $(p<0.05)$. \# $p<0.05$ represents significant variations compared the ZEA alone and KFL with ZEA treatment groups.

\subsection{KFL Inhibited LPO}

Figure 7B shows the level of LPO in liver control and treated mice. ZEA-treated mice exhibited elevated levels of LPO compared with control mice. While LPO was inhibited in KFL- and ZEA-treated mice, KFL-treated mice did not show any significant difference from the control mice. This result suggested that KFL potentially inhibits LPO in mice with ZEA-induced hepatotoxicity.

\subsection{Effect of KFL on Antioxidant Enzymes}

Mammalian cells, including hepatocytes, have developed a defense system against oxidative stress injury by enhancing the antioxidant enzymes. Levels of liver SOD, CAT and GSH were considerably low in the group in which ZEA was administered as compared 
to the control group $(p<0.05)$. These levels were markedly augmented in the KFL with ZEA-treated mice $(p<0.05$ or $p<0.01)$ (Figure 7C-E). The above-mentioned results verified the suppressive role of KFL in ZEA-induced oxidative stress in liver.

\subsection{Influence of KFLon Pathological Morphology of the Liver}

As shown in Figure 8A, pathological alterations of the liver were inspected using H\&E staining. Histopathological examination of liver sections in normal control group revealed normal hepatocyte distribution in linear hepatic cords with apparent nuclei, central vein and portal triad (panel a). In group treated with ZEA inflammatory cells were present with extensive inflammatory foci, and dispersed inflammation with severe necrosis of the tissue, interstitial edema, as well as loss of integrity. Inflammatory infiltrates were categorized into diffused and focal (panel b), we also found bi-nucleated hepatocytes, hemorragh in the sinusoids spaces, congestion of sinusoids and in the central vein, and hepatic cell death (panel c). For KFL with ZEA-treated groups, minimal necrosis, a significant decrease in sinusoidal congestion, cloudy swelling in the hepatic cells and areas of regeneration were noted (panel d). Mice in which KFL was injected constantly revealed inflammatory infiltrates and fibrotic lesions in negligible levels in the sections of liver which were similar to or lower compared to the control mice and retention of tissue integrity (panel c). These above data demonstrated that KFL enhanced hepato-protectivity effects in mice.
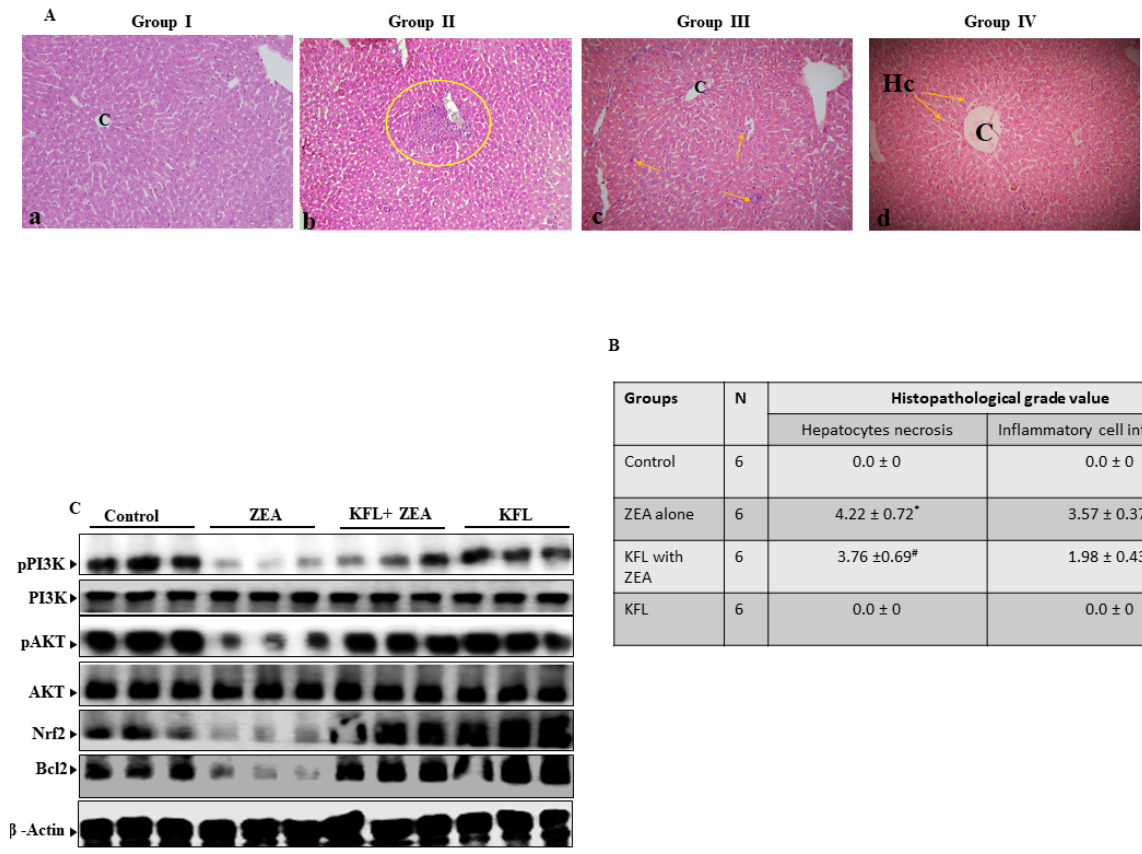

\begin{tabular}{|l|l|c|c|}
\hline \multirow{2}{*}{ Groups } & \multirow{2}{*}{$\mathrm{N}$} & \multicolumn{2}{|c|}{ Histopathological grade value } \\
\cline { 3 - 4 } & & Hepatocytes necrosis & Inflammatory cell infiltration \\
\hline Control & 6 & $0.0 \pm 0$ & $0.0 \pm 0$ \\
\hline ZEA alone & 6 & $4.22 \pm 0.72^{*}$ & $3.57 \pm 0.37^{*}$ \\
\hline $\begin{array}{l}\text { KFL with } \\
\text { ZEA }\end{array}$ & 6 & $3.76 \pm 0.69^{*}$ & $1.98 \pm 0.43^{*}$ \\
\hline KFL & 6 & $0.0 \pm 0$ & $0.0 \pm 0$ \\
\hline
\end{tabular}

Figure 8. Effect of KFL on histopathological changes in control and experimental animals. (A) Microscopic pictures of mouse liver tissue $(\mathrm{H} \& \mathrm{E}, 400 \times)$. Representative images of H\&E staining of liver tissue from mice after treatment with ZEA alone or with both ZEA and KFL: panel (a)—control, hepatocyte cords (Hc), clearly visible nuclei of hepatocytes, central vein $(\mathbf{C})$ and normal hepatocytes visible panel $(\mathbf{b}, \mathbf{c})$-ZEA alone, (B)-Circle signifies infiltrated inflammatory cells, panel (c)-KFL with ZEA, lesser sinusoidal congestion and some infiltrated inflammatory cells and panel (d) - KFL alone, marked arrow showed the normal hepatocytes and decrease of sinusoidal congestion, reduction in hepatocytes swelling exhibit recovery and retention of tissue integrity. (B) The histopathological grade values of the hepatocyte necrosis and inflammatory cell infiltration into the liver at the end of the experiment were measured $(\mathrm{n}=6)$. $(\mathrm{C})$ Inflections in pPI3K, pAkt, Nrf2 and Bcl2 proteins in albino mice. $\beta$-Actin was used as the internal control. Data are articulated as the mean values \pm SD of independent experiments $(n=6)$. ${ }^{*}$ Significant in the ZEA alone group compared with the control group $(p<0.05)$. \# $p<0.05$ represents significant variations compared to the ZEA alone and KFL with ZEA treatment groups. 


\subsection{Effect of KFL on $p P I 3 K, p A k t, N r f 2$ and Bcl2 Expression in ZEA-Treated Liver Tissue}

As seen from the Western blot analysis of pPI3K, pAkt, Nrf2 and Bcl2 in ZEA-treated liver tissue, these proteins were found to be downregulated, indicating that ZEA induced apoptosis by oxidative stress and that the activation of pPI3K, pAkt, Nrf2 and Bcl2 was effectively upregulated upon KFL treatment in the mouse liver (Figure 8B). Therefore, the results show that the effect of KFL on ZEA is mainly through regulating PI3K/Aktmediated Nrf2 expression.

\section{Discussion}

The molecular mechanisms of mycotoxin-induced toxic effects have been identified, and it has been shown that oxidative stress and accumulation of free radicals are involved in mycotoxin toxicity [30]. Undoubtedly, the discrepancy between free radicals and antioxidant defense systems can lead to chemical impairments in DNA, lipids and proteins, as has been seen in mycotoxins exposure. In this study, we determined that KFL might be a novel factor influencing the pathological condition during ZEA-induced hepatic injury. In this investigation, we examined whether ZEA treatment had a significant impact on HepG2 cell viability. However, this oxidative stress was decreased with KFL treatment, indicating that ZEA increases oxidative stress and that KFL could significantly alleviate overproduction of oxidative stress signals. These data suggest that KFL could inhibit ZEA-induced oxidative stress cell death.

In the growth factor superfamily, PI3K is an essential signal transduction molecule. The phosphorylation of its serine and threonine residues activates Akt with the help of PI3K-dependent kinase (PDK). Numerous reports have shown that PI3K/Akt signaling can regulate ROS expression and cellular oxidative stress pathways [31-33]. It provides a survival signal that allows Keap-1 to release of Nrf2 and its succeeding translocation. It also regulates ROS-dependent activation of Nrf2 under certain stresses, such as oxidative stress. On the contrary, some researchers postulated that certain kinase pathways, including PI3K, can mediate the activation of Nrf2-ARE, independent of oxidative stress [34,35]. To examine whether KFL upregulates HO-1 through Nrf2 activation, protein was isolated, and Nrf2 protein expression was inspected through western blotting. The outcomes revealed that KFL supplementation noticeably augmented Nrf2 protein expression in the nucleus, suggesting that KFL may stimulate HO-1 expression by regulating Nrf2 signaling. We utilized Nrf2 knockdown cells to determine whether inhibiting Nrf2-regulated signaling ameliorated HO-1 expression induced by KFL. It was noted that inhibition of Nrf2 profoundly attenuated KFL-triggered HO-1 expression. Therefore, we suggested that KFL exerts antioxidant functions through upregulating HO-1 expression via Nrf2.

We hypothesized that PI3K/Akt regulates KFL in ZEA-treated cells. KFL supplementation markedly augmented the phosphorylation status of Akt protein, suggesting that heightening Akt protein phosphorylation may be implicated in KFL-stimulated HO-1 expression. To investigate the function of PI3K/Akt pathway, a specific PI3K/Akt inhibitor, LY29400, was used for HepG2 together with KFL with ZEA. The outcomes revealed that KFL inhibited PI3K/Akt and Nrf2 expression. Moreover, we assessed whether PI3K/Akt plays an essential role in decreasing ROS production via KFL. Fluorescence assessment demonstrated that blocking the PI3K/Akt with LY294002 ameliorated the ROS-decreasing ability of KFL in HepG2 cells in causing oxidative stress induced by ZEA, and this may be implicated in the downregulation of Nrf2 expression. Consequently, we suggest that the PI3K/Akt-signaling cascade plays an essential function in KFL-triggered HO-1 expression by mediating Nrf2 in ZEA-induced oxidative stress.

Mycotoxins, such as ZEA, could lead to immune system, oxidative and inflammatory injuries due to their physical and biological effects [36,37]. Close relations between oxidative stress, inflammatory reactions and the immune system (for example, TNF- $\alpha$, IL- 6 and IL-1 $\beta$ activation and increase) have been reported [37]. The current study reveals that KFL noticeably decreased TNF- $\alpha$, IL- 6 and IL- $1 \beta$ levels in animals in which ZEA 
was administered as compared to control animals. Thus, this decrease is caused by the inflammatory mediators of anti-inflammatory KFL mechanism.

Liver is a primary target organ for toxicity. ZEA myotoxicity is implicated in oxidative injury, which plays a crucial role in biochemical changes in the liver [38,39]. Loss of hepatospecific enzymes in blood serum has been considered an indicator of hepatic dysfunction and damage. Most importantly, ALT, AST and ALP are key markers in identifying hepatic injury [40]. In this study, we noticed a marked augmentation in ALT, AST and ALP levels in ZEA-injected mice compared to control mice, perhaps resulting from damage to the hepatocyte membrane. This may be due to ZEA-induced free radical damage in the lipid membrane of hepatocytes, as these enzymes in the cytosol are released into the bloodstream, indicating liver damage [41]. Nonetheless, pre-administration of KFL markedly decreased changes in these hepatic markers by ZEA via its membrane-stabilization properties against ROS-mediated oxidative hepatic injury. Our study suggests that KFL diminishes cellular oxidative stress/ROS levels and protects against liver injury.

Antioxidants can compete with other oxidizable substances at moderately low concentrations and considerably decrease oxidation. The physiological process of antioxidants is to provide a defense mechanism to the cellular components from injuries due to ROS and free radicals. Recent reports have stated that the accumulation of oxidative stress signals, free radicals and ROS plays a vital role in the development of numerous ailments, including cancer [42,43]. The protective effects of antioxidants, which are mostly of natural origin, have been noted to combat the toxic effects of numerous mycotoxins [30].

Studies in vivo and in vitro have demonstrated that ZEA increases MDA levels via induction of antioxidant mechanisms, such as decrease in activity of GSH and SOD and enhancing activities of GPx and CAT $[37,44]$. Latter enzymes are implicated in the intracellular antioxidant activity of $\mathrm{H}_{2} \mathrm{O}_{2}$; thus, the augmentation of GPx and CAT functions are relatable to the intracellular mechanism which diminishes ROS accumulation triggered by ZEA [37]. The ZEA-mediated decrease in the levels of antioxidants in hepatic tissue is well corroborated with our present results. This may be due to the high levels of ZEA-induced ROS generation and the formation of ZEA-glutathione conjugates, which causes severe depletion of glutathione and facilitates its subsequent reduction in the liver. Pre-administration of KFL has been shown to exert a protective mechanism by preventing the depletion of SOD, CAT and GSH, which leads to increased antioxidant levels. This may be due to the ability of KFL to protect against oxidative damage, inhibit membrane peroxidation and exhibit membrane stabilizing properties.

Hepatic injury stimulated via ZEA-caused oxidative stress causes apoptosis in cells. Caspase-3 and Bcl-2 are imperative proteins in the stimulation of the apoptotic pathway [45]. We inspected the mechanisms of action of KFL against ZEA-triggered cytotoxicity. The outcomes revealed that KFL partially reversed ZEA-mediated gene alterations in cleaved caspase-3, cleaved PARP and Bcl-2. Moreover, ZEA can cause HepG2 death by provoking cell apoptosis. Thus, it is feasible that KFL protects against ZEA damage by blocking the apoptotic pathway. KFL could also enhance the DNA repair pathway.

\section{Experimental Section}

\subsection{Reagents}

Agents used in this study are: 3-(4,5-dimethylthiazol-2-yl)-2,5-diphenyltetrazolium bromide or also known as MTT, LY294002 (L9908), Kaempferol (60010) and Zearalenone (Z2125) (Sigma-Aldrich (St. Louis, MO, USA). 2'7'-dichlorodihydrofluorescein diacetate (DCFH2-DA; CAS 4091-99-0) and deoxynucleotidyl transferase dUTP nick end labelling (TUNEL) staining kit (Roche, cat. no. 11684817910). Antibodies against pAkt (\# 44-621G), Akt (\# 44-609G), pPI3K (\#PA5-104853), PI3K (\# PA5-29220), BCL2 (\# PA5-27094), PARP (PA5-16452), HO-1 (\# PA5-77833), NQO1 (\# PA5-82294), pNrf2 (\# PA5-105664), $\beta$-actin (\# PA5-78716) and Lamin B1 (\# PA5-19468) were sourced from Invitrogen; Thermo Fisher Scientific, Inc. (Waltham, MA, USA). Anti-cleaved caspase-3 (ab32042) antibody was 
purchased from Abcam (Branford, CT, USA). Lipofectamine 2000 (11668027) and Nrf2 siRNA were procured from Thermo Fisher Scientific, Inc. (Waltham, MA, USA).

\subsection{Cell Culture}

HepG2 cells were obtained from the American Type Culture Collection (Virginia, USA), plated DMEM/F 12 medium containing 10\% FBS (HyClone, Logan City, UT, USA) and cultured at $37^{\circ} \mathrm{C}$ with $5 \% \mathrm{CO}_{2}$.

\subsection{Cell Culture Treatment}

KFL and ZEA were suspended in serum-free medium. Cells were seeded onto plates and then with KFL, ZEA or a mixture was added over $24 \mathrm{~h}$ in triplicates in each group. Cells were added to a solution of $0.25 \%$ trypsin (w/v) and $0.52 \mathrm{mM}$ EDTA (Cat. no: R001100, Thermo, Waltham, MA, USA).

\subsection{Animals}

\subsubsection{Ethics Statement}

The care and maintenance of investigational animals were in compliance with the guidelines, ethical policies and procedures approved by the ethics committee of the King Faisal University (Approval no. 71507).

\subsubsection{Animal Experimental Design and Treatment}

Twenty-four albino male mice weighing 25-30 gm were procured from Charles River Laboratories (Écully, France). The animals were maintained at a temperature of $22 \pm 2{ }^{\circ} \mathrm{C}$ in a normal laboratory atmosphere with a $12 / 12 \mathrm{~h}$ light/dark cycle with access to food and water. Animals were randomly divided into 4 groups of 6 mice each. Each group comprised of six animals. The first group of animals was treated with saline (control), and the second group of animals was orally challenged with ZEA $(40 \mathrm{mg} / \mathrm{kg} \mathrm{wt})$ from the second week to the end of the treatment process. The third group of animals was treated with KFL (50 mg/ $\mathrm{kg} \mathrm{wt}$ ) alone in the first week, and from the second week, each animal was treated for 14 days by oral gavage (without anesthesia) with ZEA $(40 \mathrm{mg} / \mathrm{kg} \mathrm{wt})$ and with KFL ( $50 \mathrm{mg} / \mathrm{kg} \mathrm{wt}$ ) $4 \mathrm{~h}$ later. The fourth group served as the drug control, and animals were treated with KFL from the second week to the end of the experiment.

Animals were sedated by administering ether and were sacrificed at the experiment endpoint. Blood was collected via cardiac puncture, and serum was separated and stored at $-80^{\circ} \mathrm{C}$ for pro-inflammatory cytokine and biochemical analyses. Livers were excised and weighed accurately with the help of a sensitive balance (Nimbus, MK, UK). The livers were homogenized in $0.1 \mathrm{M}$ Tris- $\mathrm{HCl}$ buffer ( $\mathrm{pH}$ 7.4) for subsequent assessment of biochemical parameters.

\subsection{Viability Assay}

MTT assay was used to assess the viability of the cells. These cells were then maintained in wells of a 12-well plate, at $4 \times 10^{5}$ cells /well, and exposed to various treatments. This was followed by further incubating the cells for $2 \mathrm{~h}$ of PBS containing $400 \mu \mathrm{L}$ of MTT $(0.5 \mathrm{mg} / \mathrm{mL})$. After removing medium, the developed formazan product was liquefied in DMSO $(400 \mu \mathrm{L}$ ). Finally, a microplate reader (Winoosky, VT, USA) was used to determine the absorbance of each well at $570 \mathrm{~nm}$. Untreated cells were used as a control for cell viability (set at $100 \%$ ).

\subsection{Preparation of Cytoplasmic and Nuclear Extracts}

The cell pellets were resuspended in Buffer I for $5 \mathrm{~min}$ to prepare the cytoplasmic extracts. Buffer I consisted of $25 \mathrm{mM}$ HEPES pH 7.9, $5 \mathrm{mM} \mathrm{KCl}, 0.5 \mathrm{mM} \mathrm{MgCl} 2$, and $1 \mathrm{mM}$ dithiothreitol (DTT). This suspension was then mixed with the same amount of Buffer II consisting of $25 \mathrm{mM}$ HEPES pH 7.9, $5 \mathrm{mM} \mathrm{KCl}, 0.5 \mathrm{mM} \mathrm{MgCl}$, and $1 \mathrm{mM}$ DTT. Additionally, protease and phosphatase inhibitors supplemented with $0.4 \%(\mathrm{v} / \mathrm{v}) \mathrm{NP} 40$ 
were mixed with the suspension. The obtained suspension samples were incubated at $4{ }^{\circ} \mathrm{C}$ for $15 \mathrm{~min}$ with rotation. Then lysates were centrifuged at $2500 \mathrm{rpm}$ at $4{ }^{\circ} \mathrm{C}$ for $5 \mathrm{~min}$ in a microfuge. After that, the supernatants were transferred to new Eppendorf tubes. Buffer II was used to clean the pellets once, and the supernatant was added to the cytoplasmic protein tube. To remove residual nuclei, again, the lysates were centrifuged again at $4{ }^{\circ} \mathrm{C}$ at $10,000 \times g$ for $5 \mathrm{~min}$, and they were transferred to new Eppendorf tubes.

The pellets obtained from cytoplasmic extraction were subjected to incubation with Buffer III for nuclear extraction. In addition to protease and phosphatase inhibitors, Buffer III comprised of HEPES $25 \mathrm{mM}, \mathrm{pH}$ of $7.9, \mathrm{NaCl}-400 \mathrm{mM}, 10$ percent of sucrose or dextrose, $0.05 \% \mathrm{NP}-40$, and $1 \mathrm{mM}$ DTT. The lysates were rotated at $4{ }^{\circ} \mathrm{C}$ for $1 \mathrm{~h}$ and then centrifugation was carried out at $4{ }^{\circ} \mathrm{C}$ at $1000 \mathrm{rpm}$ for $10 \mathrm{~min}$. After this step, the collected supernatants contained nuclear proteins.

\section{7. siRNA Transfection}

Transfection with Nrf2 siRNA was performed with a $5^{\prime}-3^{\prime}$ sequence targeting human Nrf2 siRNA. HepG2 cells were loaded at $1.5 \times 10^{5}$ cells per well into 6-well plates, and transfection was conducted using Lipofectamine 2000, based on the instructions in the manufacturer's protocol. Shortly, an appropriate amount of Nrf2 siRNA and $5 \mu \mathrm{L}$ Lipofectamine 2000 in $250 \mu \mathrm{L}$ serum-free DMEM/12 medium was prepared in individual RNase-free tubes. After 5 min incubation, siRNA and Lipofectamine were combined and incubated for $20 \mathrm{~min}$ and supplemented to each well. After incubation with $100 \mathrm{pM}$ siRNA per well for $24 \mathrm{~h}$, KFL and/or ZEA was added to the cells for $24 \mathrm{~h}$ for protein analysis.

\subsection{Western Blotting}

After treatment, cells were harvested and then washed once with cold PBS, after which cytoplasmic, nuclear and total extracts were prepared in the aforementioned manner. In each sample, to detect the protein status, a Bio-Rad protein assay was used, and bovine serum albumin (BSA) was used as the reference standard. SDS-PAGE (8-15\%) was used to resolve equal amounts of protein $(50 \mu \mathrm{g})$, and the proteins were transferred to nitrocellulose membranes overnight. Five-percent skimmed milk was used for blocking the membranes at $37^{\circ} \mathrm{C}$ for $30 \mathrm{~min}$, after which the membranes were readily incubated with the indicated primary antibodies for $2 \mathrm{~h}$. After this, a horseradish peroxidase-conjugated goat anti-mouse or anti-rabbit secondary antibody was incubated with the nitrocellulose membranes for $1 \mathrm{~h}$, and an enhanced chemiluminescence substrate was used to develop the membranes (Pierce Biotechnology, Rockford, IL, USA). A LI-COR chemiluminescence imaging system (3600-00-C-Digit Blot Scanner) was used to examine the samples. Image Studio Lite software (LI-COR Biosciences, Lincoln, NE, USA) was used to generate the graphs of the densitometric band intensities with normalization to the intensity of the untreated control band, which was set to 1 .

\subsection{DNA Fragmentation Assay}

One of the hallmarks of apoptotic cell death is the fragmentation of nuclear DNA into nucleosomal units. It occurs in response to various apoptotic stimuli in a wide variety of cell types. Here we determine the DNA fragmentation in HepG2 cells upon KFL and/or ZEA treatment, the Cell Death Detection ELISA PLUS kit (Roche Applied Science, Branford, CT, USA) was used as per to the recommendation of the manufacturer and as mentioned previously $[46,47]$.

\subsection{TUNEL Assay}

HepG2 cells at the logarithmic growth stage were loaded in a six-well plate and supplemented with ZEA or KFL. After that, the medium was removed, and the cells were cleaned with PBS and processed with $4 \%$ paraformaldehyde for $20 \mathrm{~min}$ and the paraformaldehyde was removed, the cells re-washed with PBS. Afterwards, the cells were incubated with TUNEL reagent (11684817910, Roche, Mannheim, Germany). Following 
to the PBS wash, cells were counterstained with $0.1 \mu \mathrm{g} / \mathrm{mL}$ DAPI for $5 \mathrm{~min}$. Finally, cells were examined under a fluorescence microscope. All morphometric studies were executed three times. TUNEL-positive cells were detected as brilliant green, and the cell nuclei were detected through UV light microscopy at $454 \mathrm{~nm}$. Images were obtained through microscopy (200× magnification), and a Leica D6000 fluorescence microscope was used for measurement (Leica, Wetzlar, Germany).

\subsection{Real-Time Polymerase Chain Reaction (RT-PCR)}

The KFL-injected cells were cleaned with PBS and tRNA was isolated from HepG2 cells using TRIzol reagent (Invitrogen, Carlsbad, CA, USA). We then converted RNA to cDNA using a PrimeScript RT reagent kit as per the recommended guidelines of the manufacturer (Takara Bio, Shiga, Japan). Real-time qPCR was performed using SYBR Green system (Applied Biosystems, Foster City, CA, USA) and a ViiA-7 Applied Biosystem (Carlsbad, CA, USA). The mRNA expression in all genes was standardized to the expression of $\beta$-actin housekeeping gene. The primer sequences were as follows: Nrf2: sense, $5^{\prime}$ CATCCAGTCAGAAACCAGTGG- $3^{\prime}$ and antisense, $5^{\prime}$-GCAGTCATCAAAGTACAAAGCAT$3^{\prime}$; HO-1: sense, 5' -CTTCTTCACCTTCCCCAACA-3' and antisense, $5^{\prime}$-ATTGCCTGGATGTG CTTTTC-3'; NQO1: sense, 5' - GGGATCCACGGGGACATGAATG-3' and antisense, 5' ATTTGAATTCGGGCGTCTGCTG- ${ }^{\prime}$; and $\beta$-actin: sense, $5^{\prime}$-GGAAATCGTGCGTGACATTA$3^{\prime}$ and antisense, 5'-GGAGCAATGATCTTGATCTTC-3'. The mRNA expression status (fold change) was determined between groups by $2-\Delta \Delta \mathrm{Ct}$ value compared with the non-treat (NT) samples was determined.

\subsection{Analysis of Pro-Inflammatory Cytokines}

The cytokine status of serum was inspected by implementing a sandwich ELISA (enzyme-linked immunosorbent assay) technique using commercial kits (Thermo Fisher Scientific Co., Waltham, MA, USA). TNF- $\alpha$, IL- 6 and IL- $\beta 1$ in the serum were investigated via commercial cytokine ELISA kits (cat\# KMC0061 for IL-6; cat\# KMC3011 for TNF- $\alpha$; cat \# BMS6002 IL- $\beta 1$ ) obtained from Invitrogen (USA). Cytokine status was inspected in regards with the recombinant biotinylated murine TNF- $\alpha$ and IL- 6 standards supplied with the kits. These kits were manufactured by Endogen-Pierce and distributed by Fisher Thermo Scientific Co., and all controls and standards mentioned in the manufacturer's kit were implemented.

\subsection{Biochemical Analysis}

The liver was excised and homogenized $(10 \% \mathrm{w} / \mathrm{v})$ with chilled $0.1 \mathrm{M}$ sodium phosphate buffer ( $\mathrm{pH}$ 7.4). Then, the homogenate was centrifuged twice at $11200 \mathrm{rpm}$ for $20 \mathrm{~min}$ at $4{ }^{\circ} \mathrm{C}$ to obtain an enzyme fraction. The supernatant was used for biochemical studies. The aspartate aminotransferase [48], alanine aminotransferase (ALT) and alkaline phosphatase [49] activities were inspected using the manufacturer's protocols (Spectrum Diagnostics, Obour, Egypt). GSH, SOD and CAT assay kits (Cayman Chemical, Ann Arbor, MI, USA) were utilized for analysis.

\subsubsection{Measurement of $\mathrm{H}_{2} \mathrm{O}_{2}$}

The amounts of $\mathrm{H}_{2} \mathrm{O}_{2}$ were measured by $\mathrm{H}_{2} \mathrm{O}_{2}$ assay kit (cat. no. AB102500). In the presence of Horse Radish Peroxidase (HRP), the OxiRed Probe reacts with $\mathrm{H}_{2} \mathrm{O}_{2}$ to produce product with color. In 96-well plates, normal diluents $(100 \mu \mathrm{L})$, lysates collected from each sample $(100 \mu \mathrm{L})$ and $100 \mu \mathrm{L}$ of reaction mixture $(50 \mu \mathrm{L}$ working enzyme solution and $50 \mu \mathrm{L}$ probe) were added; the plates were then incubated for $1 \mathrm{~h}$ at room temperature on a plate shaker. At $590 \mathrm{~nm}$, the optical density was read.

\subsubsection{Measurement of LPO}

The levels of LPO were detected by LPO kit ((cat. no. ab133085). The lipid hydroperoxide (LPO) content was determined in the liver prepared from ZEA-treated mice pretreated 
with or without KFL using the commercial LPO assay package. Calculating malondialdehyde (MDA) and 4-hydroxy nonenal (4-HNE), degradation products of polyunsaturated fatty acids (PUFAs) hydroperoxides, lipid peroxidation is quantified at $500 \mathrm{~nm}$, the optical density was read.

\subsubsection{Measurement of GSH}

Total intracellular glutathione (GSH+GSSG) using a glutathione assay kit based on Ellman's reagent, according to the manufacturer's protocol (Cat\# 703002, Cayman Chemical, Ann Arbor, MI, USA). GSH concentration of samples determined by end-point method (read the plate at $450-414 \mathrm{~nm}$ after $25 \mathrm{~min}$ ).

\subsection{Histopathology Examination}

The harvested livers of mice were fixed in formalin, dried with 100\%, 95\% and $75 \%$ alcohol, and implanted in paraffin wax. Tissue slices $(0.2 \mu \mathrm{m}$ thick) were washed in xylene to eradicate paraffin and spotted with haematoxylin and eosin (H\&E). Finally, the slices were cleaned with water to eliminate excess H\&E before they were stained with Masson's trichrome stain to assess the morphological and fibrotic alterations in the liver, where blue staining indicated collagen thickening.

\subsection{Statistical Analysis}

Statistical analyses were performed using GraphPad Prism software version 6.0 (GraphPad Software Inc., San Diego, CA, USA), and for comparison of three groups, one-way ANOVA was used. Data are represented as the mean $\pm \mathrm{SD}$, and $p<0.05$ was regarded as significant.

\section{Conclusions}

Our results showed that using kaempferol as an additive could effectively remove ZEA contamination in feed and protect against the toxic damage of ZEA both in vivo as well as in vitro. The findings of the current research revealed KFL's therapeutic and prophylactic efficacy against ZEA-promoted oxidative hepatic damage via its strong antioxidant properties. KFL ameliorates ZEA-induced alterations in the liver via Nrf2 activation by PI3K/Akt-mediated pathway. Moreover, Nrf2 has emerged as a target factor for a wide variety of genes which are beneficial in detoxification and elimination of ZEA-induced liver oxidative damage. Further in-depth studies may establish bioactive KFL as a potential contender for the treatment of ZEA-induced oxidative stress-with hepatic complications in the future.

Supplementary Materials: Supplementary Materials are available online at https://www.mdpi. com/1422-0067/22/1/217/s1.

Author Contributions: Conceptualization, P.R. and R.B.A.; methodology, investigation, data curation, formal analysis, review and editing, F.J.A.-S.; software, A.M.S.; validation, P.R., R.B.A. and M.E.M.; formal analysis, M.A.E.; investigation, P.R.; resources, F.J.A.-S.; data curation, P.R.; writing—original draft preparation, P.R.; writing—-review and editing, S.Y.A.-R.; visualization, G.M.B.; supervision, P.R.; project administration, P.R.; funding acquisition, P.R. All authors have read and agreed to the published version of the manuscript.

Funding: The authors extend their appreciation to the Deputyship for Research \& Innovation, Ministry of Education in the Kingdom Saudi Arabia for funding this research work through the project number (IFT20091).

Conflicts of Interest: The authors declare no conflict of interest. 


\section{References}

1. $\quad$ Rajput, S.A.; Sun, L.; Zhang, N.-Y.; Khalil, M.M.; Ling, Z.; Chong, L.; Wang, S.; Rajput, I.R.; Bloch, D.M.; Khan, F.A. Grape seed proanthocyanidin extract alleviates aflatoxinB1-induced immunotoxicity and oxidative stress via modulation of NF- $\mathrm{KB}$ and Nrf2 signaling pathways in broilers. Toxins 2019, 11, 23. [CrossRef] [PubMed]

2. Fernández-Cruz, M.L.; Mansilla, M.L.; Tadeo, J.L. Mycotoxins in fruits and their processed products: Analysis, occurrence and health implications. J. Adv. Res. 2010, 1, 113-122. [CrossRef]

3. Lee, H.-J.; Park, J.-H.; Oh, S.-Y.; Cho, D.-H.; Kim, S.; Jo, I. Zearalenone-induced interaction between PXR and Sp1 increases binding of Sp1 to a promoter site of the eNOS, decreasing its transcription and NO production in BAECs. Toxins 2020, 12, 421. [CrossRef]

4. Yoon, J.E.; Lee, K.Y.; Seok, J.S.; Cheng, W.N.; Kwon, H.C.; Jeong, C.H.; Han, S.G. Zearalenone induces endoplasmic reticulum stress and modulates the expression of phase I/II enzymes in human liver cells. Toxins 2020, 12, 2. [CrossRef]

5. Skiepko, N.; Przybylska-Gornowicz, B.; Gajęcka, M.; Gajęcki, M.; Lewczuk, B. Effects of deoxynivalenol and zearalenone on the histology and ultrastructure of pig liver. Toxins 2020, 12, 463. [CrossRef]

6. Ding, Y.; Wang, L.; Song, J.; Zhou, S. Protective effects of ellagic acid against tetrachloride-induced cirrhosis in mice through the inhibition of reactive oxygen species formation and angiogenesis. Exp. Ther. Med. 2017, 14, 3375-3380. [CrossRef]

7. Li, D.; Zhao, D.; Du, J.; Dong, S.; Aldhamin, Z.; Yuan, X.; Li, W.; Du, H.; Zhao, W.; Cui, L. Heme oxygenase-1 alleviated nonalcoholic fatty liver disease via suppressing ROS-dependent endoplasmic reticulum stress. Life Sci. 2020, 253, 117678. [CrossRef]

8. Huixian, F. A review on intervening PI3K/Akt signal pathway against liver with TCM medicine. Clin. J. Chin. Med. 2018, $72,72-79$.

9. Sun, K.; Luo, J.; Guo, J.; Yao, X.; Jing, X.; Guo, F. The PI3K/Akt/mTOR signaling pathway in osteoarthritis: A narrative review. Osteoarthr. Cartil. 2020, 28, 400-409. [CrossRef]

10. Spangle, J.M.; Roberts, T.M.; Zhao, J.J. The emerging role of PI3K/Akt-mediated epigenetic regulation in cancer. Biochim. Biophys. Acta (BBA) Rev. Cancer 2017, 1868, 123-131. [CrossRef] [PubMed]

11. Ali, T.; Kim, T.; Rehman, S.U.; Khan, M.S.; Amin, F.U.; Khan, M.; Ikram, M.; Kim, M.O. Natural dietary supplementation of anthocyanins via PI3K/Akt/Nrf2/HO-1 pathways mitigate oxidative stress, neurodegeneration, and memory impairment in a mouse model of Alzheimer's disease. Mol. Neurobiol. 2018, 55, 6076-6093. [CrossRef]

12. Zhuang, Y.; Wu, H.; Wang, X.; He, J.; He, S.; Yin, Y. Resveratrol attenuates oxidative stress-induced intestinal barrier injury through PI3K/Akt-mediated Nrf2 signaling pathway. Oxidative Med. Cell. Longev. 2019, 2019, 7591840. [CrossRef] [PubMed]

13. Gong, G.; Yin, L.; Yuan, L.; Sui, D.; Sun, Y.; Fu, H.; Chen, L.; Wang, X. Ganglioside GM1 protects against high altitude cerebral edema in rats by suppressing the oxidative stress and inflammatory response via the PI3K/Akt-Nrf2 pathway. Mol. Immunol. 2018, 95, 91-98. [CrossRef] [PubMed]

14. Chen, Y.-P.; Sivalingam, K.; Shibu, M.A.; Peramaiyan, R.; Day, C.H.; Shen, C.-Y.; Lai, C.-H.; Chen, R.-J.; Viswanadha, V.P.; Chen, Y.-F. Protective effect of Fisetin against angiotensin II-induced apoptosis by activation of IGF-IR-PI3K-Akt signaling in H9c2 cells and spontaneous hypertension rats. Phytomedicine 2019, 57, 1-8. [CrossRef] [PubMed]

15. Thangapandiyan, S.; Ramesh, M.; Miltonprabu, S.; Hema, T.; Jothi, G.B.; Nandhini, V. Sulforaphane potentially attenuates arsenic-induced nephrotoxicity via the PI3K/Akt/Nrf2 pathway in albino Wistar rats. Environ. Sci. Pollut. Res. 2019, 26, 12247-12263. [CrossRef] [PubMed]

16. Yang, H.-L.; Lee, C.-L.; Korivi, M.; Liao, J.-W.; Rajendran, P.; Wu, J.-J.; Hseu, Y.-C. Zerumbone protects human skin keratinocytes against UVA-irradiated damages through Nrf2 induction. Biochem. Pharmacol. 2018, 148, 130-146. [CrossRef]

17. Rajendran, P.; Rengarajan, T.; Nandakumar, N.; Palaniswami, R.; Nishigaki, Y.; Nishigaki, I. Kaempferol, a potential cytostatic and cure for inflammatory disorders. Eur. J. Med. Chem. 2014, 86, 103-112. [CrossRef]

18. Du, W.; An, Y.; He, X.; Zhang, D.; He, W. Protection of kaempferol on oxidative stress-induced retinal pigment epithelial cell damage. Oxidative Med. Cell. Longev. 2018, 2018, 1610751. [CrossRef]

19. Li, B.; Cheng, Z.; Sun, X.; Si, X.; Gong, E.; Wang, Y.; Tian, J.; Shu, C.; Ma, F.; Li, D. Lonicera caerulea L. polyphenols alleviate oxidative stress-induced intestinal environment imbalance and lipopolysaccharide-induced liver injury in HFD-fed rats by regulating the Nrf2/HO-1/NQO1 and MAPK pathways. Mol. Nutr. Food Res. 2020, 64, 1901315. [CrossRef]

20. Yao, H.; Sun, J.; Wei, J.; Zhang, X.; Chen, B.; Lin, Y. Kaempferol protects blood vessels from damage induced by oxidative stress and inflammation in association with the Nrf2/HO-1 signaling pathway. Front. Pharmacol. 2020, 11, 1118. [CrossRef]

21. Lu, C.; Xu, W.; Zhang, F.; Shao, J.; Zheng, S. Nrf2 knockdown attenuates the ameliorative effects of ligustrazine on hepatic fibrosis by targeting hepatic stellate cell transdifferentiation. Toxicology 2016, 365, 35-47. [CrossRef]

22. Liu, W.; Jing, Z.-T.; Xue, C.-R.; Wu, S.-X.; Chen, W.-N.; Lin, X.-J.; Lin, X. PI3K/Akt inhibitors aggravate death receptor-mediated hepatocyte apoptosis and liver injury. Toxicol. Appl. Pharmacol. 2019, 381, 114729. [CrossRef]

23. Long, M.; Chen, X.; Wang, N.; Wang, M.; Pan, J.; Tong, J.; Li, P.; Yang, S.; He, J. Proanthocyanidins protect epithelial cells from zearalenone-induced apoptosis via inhibition of endoplasmic reticulum stress-induced apoptosis pathways in mouse small intestines. Molecules 2018, 23, 1508. [CrossRef]

24. Xiao, Y.; Xu, S.; Zhao, S.; Liu, K.; Lu, Z.; Hou, Z. Protective effects of selenium against zearalenone-induced apoptosis in chicken spleen lymphocyte via an endoplasmic reticulum stress signaling pathway. Cell Stress Chaperones 2019, 24, 77-89. [CrossRef]

25. Cao, H.; Zhi, Y.; Xu, H.; Fang, H.; Jia, X. Zearalenone causes embryotoxicity and induces oxidative stress and apoptosis in differentiated human embryonic stem cells. Toxicol. Vitro 2019, 54, 243-250. [CrossRef] 
26. Gao, X.; Xiao, Z.-H.; Liu, M.; Zhang, N.-Y.; Khalil, M.M.; Gu, C.-Q.; Qi, D.-S.; Sun, L.-H. Dietary silymarin supplementation alleviates zearalenone-induced hepatotoxicity and reproductive toxicity in rats. J. Nutr. 2018, 148, 1209-1216. [CrossRef]

27. Reyes-Gordillo, K.; Segovia, J.; Shibayama, M.; Vergara, P.; Moreno, M.G.; Muriel, P. Curcumin protects against acute liver damage in the rat by inhibiting NF-кB, proinflammatory cytokines production and oxidative stress. Biochim. Biophys. Acta (BBA) Gen. Subj. 2007, 1770, 989-996. [CrossRef]

28. Tsai, M.-S.; Wang, Y.-H.; Lai, Y.-Y.; Tsou, H.-K.; Liou, G.-G.; Ko, J.-L.; Wang, S.-H. Kaempferol protects against propacetamolinduced acute liver injury through CYP2E1 inactivation, UGT1A1 activation, and attenuation of oxidative stress, inflammation and apoptosis in mice. Toxicol. Lett. 2018, 290, 97-109. [CrossRef] [PubMed]

29. Jadeja, R.N.; Devkar, R.V.; Nammi, S. Oxidative stress in liver diseases: Pathogenesis, prevention, and therapeutics. Oxidative Med. Cell.Longev. 2017, 2017, 8341286. [CrossRef]

30. Da Silva, E.; Bracarense, A.P.; Oswald, I.P. Mycotoxins and oxidative stress: Where are we? World Mycotoxin J. 2018, 11, 113-134. [CrossRef]

31. Le Belle, J.E.; Orozco, N.M.; Paucar, A.A.; Saxe, J.P.; Mottahedeh, J.; Pyle, A.D.; Wu, H.; Kornblum, H.I. Proliferative neural stem cells have high endogenous ROS levels that regulate self-renewal and neurogenesis in a PI3K/Akt-dependant manner. Cell Stem Cell 2011, 8, 59-71. [CrossRef]

32. Tsai, C.-Y.; Wang, C.-C.; Lai, T.-Y.; Tsu, H.-N.; Wang, C.-H.; Liang, H.-Y.; Kuo, W.-W. Antioxidant effects of diallyl trisulfide on high glucose-induced apoptosis are mediated by the PI3K/Akt-dependent activation of Nrf2 in cardiomyocytes. Int. J. Cardiol. 2013, 168, 1286-1297. [CrossRef]

33. Lim, J.H.; Kim, K.-M.; Kim, S.W.; Hwang, O.; Choi, H.J. Bromocriptine activates NQO1 via Nrf2-PI3K/Akt signaling: Novel cytoprotective mechanism against oxidative damage. Pharmacol. Res. 2008, 57, 325-331. [CrossRef]

34. Yang, H.-L.; Yang, T.-Y.; Gowrisankar, Y.V.; Liao, C.-H.; Liao, J.-W.; Huang, P.-J.; Hseu, Y.-C. Suppression of LPS-induced inflammation by chalcone flavokawain a through activation of Nrf2/ARE-mediated antioxidant genes and inhibition of ROS/NFKB signaling pathways in primary splenocytes. Oxidative Med. Cell. Longev. 2020, 2020, 3476212. [CrossRef]

35. Hseu, Y.C.; Yang, T.Y.; Li, M.L.; Rajendran, P.; Mathew, D.C.; Tsai, C.H.; Lin, R.W.; Lee, C.C.; Yang, H.L. Chalcone flavokawain A attenuates TGF- $\beta 1$-induced fibrotic pathology via inhibition of ROS/Smad3 signaling pathways and induction of Nrf2/AREmediated antioxidant genes in vascular smooth muscle cells. J. Cell. Mol. Med. 2019, 23, 775-788. [CrossRef]

36. Marin, D.E.; Taranu, I.; Burlacu, R.; Tudor, D.S. Effects of zearalenone and its derivatives on the innate immune response of swine. Toxicon 2010, 56, 956-963. [CrossRef]

37. Marin, D.E.; Pistol, G.C.; Neagoe, I.V.; Calin, L.; Taranu, I. Effects of zearalenone on oxidative stress and inflammation in weanling piglets. Food Chem. Toxicol. 2013, 58, 408-415. [CrossRef]

38. Tatay, E.; Font, G.; Ruiz, M.-J. Cytotoxic effects of zearalenone and its metabolites and antioxidant cell defense in CHO-K1 cells. Food Chem. Toxicol. 2016, 96, 43-49. [CrossRef]

39. Wu, K.; Liu, X.; Fang, M.; Wu, Y.; Gong, Z. Zearalenone induces oxidative damage involving Keap1/Nrf2/HO-1 pathway in hepatic L02 cells. Mol. Cell. Toxicol. 2014, 10, 451-457. [CrossRef]

40. Thangapandiyan, S.; Ramesh, M.; Hema, T.; Miltonprabu, S.; Uddin, M.; Nandhini, V.; Bavithra Jothi, G. Sulforaphane potentially ameliorates arsenic induced hepatotoxicity in albino Wistar rats: Implication of PI3K/Akt/Nrf2 signaling pathway. Cell Physiol. Biochem. 2019, 52, 1203-1222.

41. Chatopadhyay, P.; Pandey, A.; Chaurasia, A.K.; Upadhyay, A.; Karmakar, S.; Singh, L. Hepatic hyperplasia and damages induces by zearalenone Fusarium mycotoxins in BALB/c mice. Arq. Gastroenterol. 2012, 49, 77-81. [CrossRef]

42. Reuter, S.; Gupta, S.C.; Chaturvedi, M.M.; Aggarwal, B.B. Oxidative stress, inflammation, and cancer: How are they linked? Free Radic. Biol. Med. 2010, 49, 1603-1616. [CrossRef]

43. Zuo, L.; Zhou, T.; Pannell, B.; Ziegler, A.; Best, T.M. Biological and physiological role of reactive oxygen species-The good, the bad and the ugly. Acta Physiol. 2015, 214, 329-348. [CrossRef]

44. Liu, M.; Zhu, D.; Guo, T.; Zhang, Y.; Shi, B.; Shan, A.; Chen, Z. Toxicity of zearalenone on the intestines of pregnant sows and their offspring and alleviation with modified halloysite nanotubes. J. Sci. Food Agric. 2018, 98, 698-706. [CrossRef]

45. Yi, Y.; Wan, S.; Hou, Y.; Cheng, J.; Guo, J.; Wang, S.; Khan, A.; Sun, N.; Li, H. Chlorogenic acid rescues zearalenone induced injury to mouse ovarian granulosa cells. Ecotoxicol. Environ. Saf. 2020, 194, 110401. [CrossRef]

46. Imran, M.; Salehi, B.; Sharifi-Rad, J.; Aslam, T.; Saeed, F.; Imran, A.; Shahbaz, M.; Fokou, P.V.T.; Arshad, M.U.; Khan, H.; et al. Kaempferol: A Key Emphasis to Its Anticancer Potential. Molecules 2019, 24, 2277. [CrossRef]

47. Shanmugam, M.K.; Rajendran, P.; Li, F.; Kim, C.; Sikka, S.; Siveen, K.S.; Kumar, A.P.; Ahn, K.S.; Sethi, G. Abrogation of STAT3 signaling cascade by zerumbone inhibits proliferation and induces apoptosis in renal cell carcinoma xenograft mouse model. Mol. Carcinog. 2015, 54, 971-985. [CrossRef]

48. Srivastava, S.; Singh, M.; George, J.; Bhui, K.; Shukla, Y. Genotoxic and carcinogenic risks associated with the consumption of repeatedly boiled sunflower oil. J. Agric. Food Chem. 2010, 58, 11179-11186. [CrossRef]

49. Nayak, P.K.; Dash, U.; Rayaguru, K.; Krishnan, K.R. Physio-chemical changes during repeated frying of cooked oil: A review. J. Food Biochem. 2016, 40, 371-390. [CrossRef] 